\title{
Huge reorg of Nova Scotia's health system
}

$\mathrm{N}$ ova Scotia is cutting the number of district health authorities in the province from 10 to 2 , with the aim of reducing administration and saving \$5 million annually in senior management salaries. The new Health Authorities Act passed through the legislature in just five days.

Nova Scotia, a relatively small province with a population of 940000 , has "10 health authorities and 10 different ways of doing things," says Dr. Lynne Harrigan, vice president of medicine at Annapolis Valley Health and co-lead of the transition team responsible for recommending how physicians will operate in the new system. But the focus of the merger will be on the patient. "We will streamline processes to improve care."

Physicians' response to the merger, which was a prominent 2013 election promise from the Liberal government, has been cautious but supportive. "We're looking at it as an opportunity to work with government so patients are better served," says Kevin Chapman, director of Health Policy and Economics with Doctors Nova Scotia.

The government has made four commitments, including developing a multiyear health plan for the province that will set targets for improvement. There is also a legal requirement for the IWK Health Centre in Halifax and the provincial health board - the two authorities created by the new legislation - to prepare annual public-engagement plans to ensure community voices are heard.

Doctors have already made it clear that they don't want centralization of services to detract from the needs of local communities. "Physicians want administrative feet on the ground. They want local support," says Harrigan. "Any model we come up with will have to reflect this."

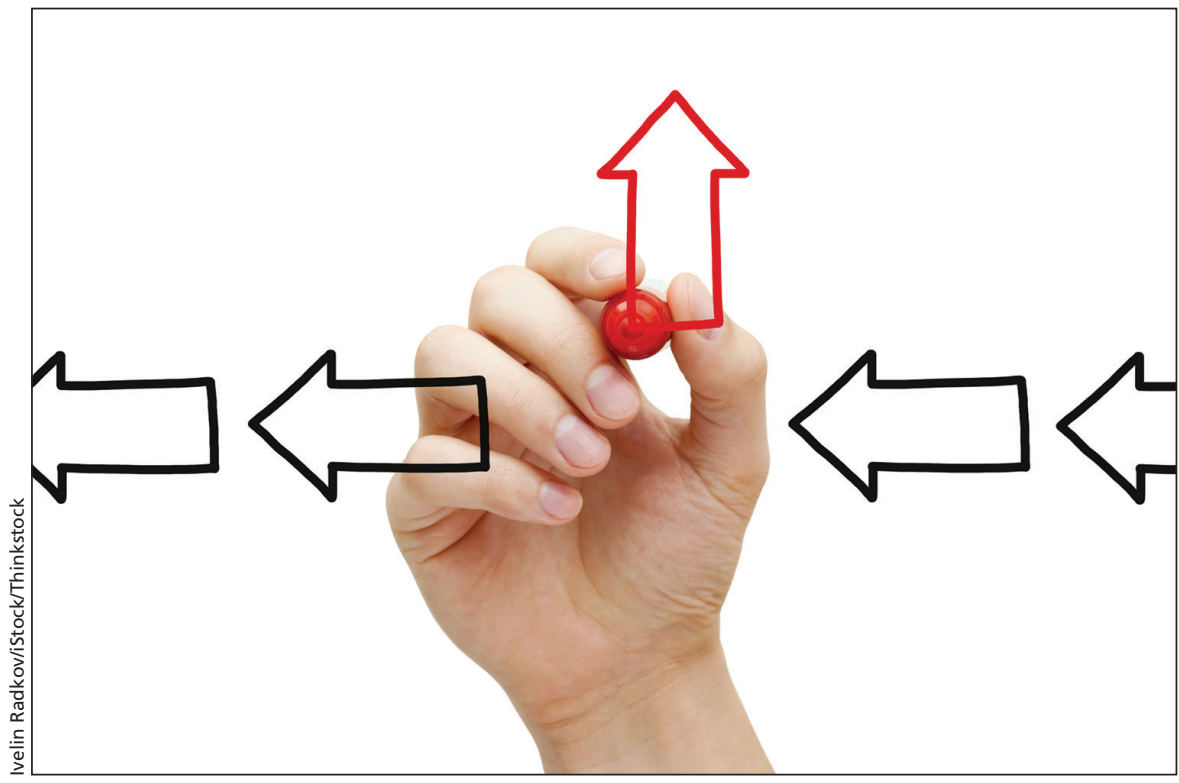

The focus of the merger from 10 health authorities to 2 will be on improving patient care.

The new physician bylaws, now being developed by the health department and Doctors Nova Scotia, are also expected to change credentialing and privileging in the province. "We want to streamline this," says Patrick Lee, CEO of the Pictou County Health Authority who is currently serving as co-lead of the provincial consolidation project.

Privileging is not now required in Nova Scotia, and physicians who want to be credentialed to work in more than one health facility must repeatedly go through the administrative process. Under the consolidated system, all physicians will likely have to be privileged, and credentialing will be simplified. Doctors Nova Scotia applauds both approaches but expressed concerns these systems could be used to restrict physicians to specific geographical locations.

That worry is unfounded, says Lee.
"We have no plans to make any of those changes."

One of the major - and controversial - changes the government has made is to reorganize the way health care workers are unionized. Four existing unions will continue to represent health workers, but they will represent only one group each. The Nova Scotia Nurses' Union, for example, will represent all nurses in the province. The move is intended to reduce the rounds of bargaining from 50 to 4 , according to the government.

The implications are already significant for the health care system, says Joan Jessome, president of the Nova Scotia Government and General Employees Union, which stands to lose 10000 members under the restructuring. "It's affected patient care today. [Staff] are all distracted." - donalee Moulton, Halifax, NB

CMAJ 2014. DOI:10.1503/cmaj.109-4928 